\title{
TECHNOLOGY AT THE CROSSROADS: A CALL FOR TRANSFORMATIVE TECHNOLOGY IN THE POST-PANDEMIC ERA
}

\author{
Ph.D. Christine Carmela R. RAMOS, \\ Mapúa University \\ PHILIPPINES, \\ Email: 1ccrramos@mapua.edu.ph,2tinrams@gmail.com
}

\begin{abstract}
Globalization is viewed in this work as a critical concept by which we understand the transition of human society into the post-pandemic era. In this vein, this paper attempts to look into the process of globalization and its central feature, technology. Technology has become a global force that affects political, social, ethical, and environmental.

The ancient Greeks, such as Plato and Aristotle, who lived in aristocratic societies, rejected discourse on technology as unworthy. Social, political, and theoretical activities, rather than technical, were deemed as the highest forms. Plato, for instance, alluded to the artisans merely as the cheapest form of metal compared to gold associated with the philosopher-rulers, while silver is equivalent to the warrior class. Technological change, defined as "progress," is seen as an inevitable process in modern history. This paper explored issues of globalization and the implications of technology, employing crucial viewpoints of Martin Heidegger, acknowledged as one of the powerful and influential philosophers of the 20th century. Specifically, this paper explored "machination (Machenschaft)" and Heidegger's Technik (Technology) or Gestell (Enframing). Machination is not just human conduct but the act of manipulation. It is a revelation of beings as a whole as exploitable and manipulable objects. The world seems to be a collection of present-at-hand thing with no intrinsic meaning or purpose, a cold place where we cannot put down any roots. All we can do is calculate and control. We observe and measure everything. We make things go faster and faster. Thus, there is a need to discuss and recognize issues related to technology. Heidegger's thoughts offer analytic tools that contribute to a critical understanding of the multidimensional effects, risks, and possibilities brought about by modernity and its globalization.
\end{abstract}

Keywords: Domination; Globalization; Modernity; Science; Technology;

\section{INTRODUCTION: TECHNOLOGY AS AN IDEOLOGY}

There have been many topics regarding the issue of science and technology. However, the author chose to approach the problem of globalization from philosophical and ethical viewpoints. The author's reflections on ethical issues articulate the relationship between globalization and technology, both of which had become inscribed to the dynamics of modernity and modern social existence. The paper explored the tripartite relationship of globalization, technology, and ethics in dealing with the spontaneous experiences of global citizens, such as the political, legal, economic, and cultural, in an accelerating phase of the level of integration comprising bonds between states.

Science and technology are not a single phenomenon. In the present era, they have become an ideology. Technology cannot mean only products such as machinery, electronics, 
or other public consumer goods. Technology includes our whole attitude toward the human world, not just as an object. It also provides knowledge and consciousness and our powers of abstraction. In the modern era, this attitude is manifested theoretically in science and technological innovation. In a broader sense, science and technology are the culture itself.

It follows that decision-making should consider the social, ethical and technological, and scientific domains (Cam 1999, 192). Since science and technology have dramatically influenced human existence and what is essential to us, it has become vital to determine their consequences to our values and aspirations. Rapid changes contest the discovery of what is fundamental to our existence. In this context, Heidegger's philosophical reflection has a crucial role.

Natural cycles are not regulated by natural rhythms anymore; instead, in an artificial environment characterized by the results of technology (Cam 1999, 197). Our present age is stamped by the latest inventions that sometimes can be overwhelming. Technology is not only the copy of the "first nature" but a "second nature," replacing nature itself. The success of technology in developing itself is faced with the inability and lack of humanistic knowledge to answer the fundamental problems of masses such as poverty, ignorance, and famine. On the other hand, rationalistic and positivistic ideas tend to take over all understanding acquired by reflection or, even more, from faith. The presence of a relation between the material and metaphysical, the physical and non-physical realms, and between heaven and earth tend to be rejected or found objectionable.

Whether individual or as species, human achievement is measured by success in mastering science and technology in this century, we cannot isolate ourselves and live without technology. Technology has influenced all matters that were considered the right of God in His creation in the past. Exact science and technology had functioned as the "savior" with the ability to save and liberate human beings from ignorance, underdevelopment, and poverty. Although the facts may show a different tendency, the rich and the poor gap has grown substantially. Science and technology have become the most distinctive symbol of human autonomy.

Humanity has separated itself from its cosmic relation and other realities. On the other hand, modernization seems to be dominated by a materialistic truth instead of a nonmaterialistic one. The priority is put on physical needs, even to the extent of destroying our spiritual ones. It might seem that the condition of civilization is unnecessarily dramatized. However, we have to realize that science and technology were developed initially to free people by solving their problems in life. If they are out of control, they create complexities and complications in life that can appear as the destruction of the environment, isolation, and the loss of sensitivity to human spirituality (Cam 1999: 19). This means that people have lost spiritual contact with each other, the environment, surrounding nature, and anything with transcendental characteristics. Modern technology has sacrificed humanity and the world together, leading to their destruction.

\section{STATEMENT OF THE PROBLEM}

What is distinctive about this paper is that the author had adopted a philosophical framework in articulating the relationship between globalization and technology, both of which had become inscribed to the dynamics of modernity and modern social existence, particularly in the Philippines. Issues of globalization and the implications of technology are brought into play employing crucial viewpoints of Martin Heidegger, acknowledged as one of the powerful and influential philosophers of the twentieth century. Risks and 
possibilities brought about by modernity and its globalization is brought into play from the perspective of Martin Heidegger.

Further, this paper deliberated on the ethical implications of globalization and technology. This study suggested that philosophy should not withdraw from the leading aspects of daily life and experience but rather could facilitate envisioning a global community that emphasized a non-violent transformation. Finally, the author also reflected on a new world ethos, the cultural ideology of consumerism, e.g., the loss of the sense of "real" in favor of "imaginary" things.

\section{METHODOLOGY}

This paper attempted to look into the process of globalization and its central feature, technology. Risks and possibilities brought about by modernity and its globalization is brought into play from the perspective of Martin Heidegger.

What is Heidegger's stature as a thinker? This is too difficult to answer. Nevertheless, his influence is immense on Rudolf Bultmann, Karl Rahner, Paul Tillich, Ludwig Binswanger, Emil Staiger, and the writings of Richard Rorty and H.L. Dreyfus and many others.

For Heidegger, the greatest danger is that calculative thinking someday may come to be accepted and practiced as the only way of thinking. Heidegger calls the utter availability and sheer manipulability the essence of technology. The danger is not the destruction of nature or culture but a restriction in our way of thinking, a leveling of our understanding.

\section{FINDINGS: CYBERAGE AND GLOBALIZING TRENDS}

Global communications and technology mediate the chronic intensification of patterns of interconnectedness to which it gives rise. Globalization, as viewed in this work, is a critical concept. This study suggested that philosophy should not retreat from the leading aspects of daily life and experience. Instead, it could facilitate envisioning a global community that emphasized a non-violent transformation and social and political creativity in planning and using science and technology.

Our power and efficiency are continually escalating -- but questioning and reflection are declining. Quality is reduced to quantity. This mathematization of the world does away with all sacredness. Heidegger speaks of the "flight of the gods" and "the death of the moral, Christian god." In this technological perspective, ultimate goals like serving God, society, our fellows, or even ourselves no longer make sense. Thus, humanity becomes a resource to be used -- but notably, enhanced -- like any other.

A. Heidegger's philosophy underscored that humanity is reduced as a stockpile in service to, and on-call, for technological purposes. Revealing or "exploitation" of nature happens. However, revealing never comes to an end. The crux of that methodology lies in its character as an explicating (Erklaren) of the actual relationships subsisting among the elements composing an object-sphere that appears within the purview of the ground plan that orients and governs specific work. The plan provides a fixed perspective that, as it was, captures reality and sets it over against the viewer in some kind of predictable pattern. However, the reality that is schematized in advance is itself anything but static and straightforward. No matter where or under what aspect it is grasped, it is filled with complexity and perpetually changing.

Science needs, therefore, beyond its rigorous adherence to its projected ground plan, a way of proceeding that can allow it to deal with complexity and with a change of every sort 
by discerning among all the elements in its object-sphere, precisely in their changefulness, interrelations that it can categorize and hence comprehend (Lovitt and Lovitt 1995, 275). This clarifying explication (Erklarung) that is wrought out through the methodology of modern science is constitutive for science itself. Science remains aware that the laws that it propounds, at least insofar as its knowledge of them are concerned, and are not laws in an absolute sense but "hypotheses." They have established bases for their work, fixed beforehand by available data, and accepted adequately as deserving of belief.

However, at the same time, they are always in need of verification and constantly being tested, whether through experiment or the interpretation of other sources, even as they are being applied. Thus, the explication of reality that science accomplishes has always a twofold character. "It accounts for an unknown through a known, "Heidegger $(1977,121)$ says, "and at the same time it verifies that known utilizing that unknown."

Through the application of this method, the extent of the reality that has been brought into the horizon of scientific knowledge, e.g., the range of that which has become secured as intelligible in the light of one ground plan and one set of hypotheses or another, steadily grows. It is just this reliably secured knowledge that modern science as research is bent on achieving. How scientific work structures itself in carrying itself forward is explicitly determined by that goal. New findings do not so follow those already made as merely to augment their number.

Instead, they throw light upon them, now confirming the interpretation accorded to them, now demanding the revision of that interpretation. As this happens, earlier discoveries and hypotheses are taken up into those that succeed them (Heidegger 1977, 124). Science, we might say, builds itself forward.

For science in the highly standardized and specialized form that it has now assumed, rich opportunities lie open. Results of research can be readily exchanged and confirmed; joint projects can be undertaken. Particular methodologies can be borrowed or combined across the disciplinary lines, and the knowledge and talents of research workers can be readily shared. Thus, far from losing themselves in fragmentation due to their specialization, the sciences are, through its means, actually establishing the solidarity and unity appropriate to them. More and more, calculating is becoming dominant in every science. Increasingly, the information handled in all the sciences and exchanged among them is stripped of extraneous details regarding the phenomena it concerns. The computer is assuming an increasingly central place in scientific research, and data processing is becoming allimportant.

B. Ihde $(1991,55)$ explains further Heidegger's reversal of the usual understanding of the relationship between science and technology. This is to say, and if the dominant view claims that technology is applied sciences, then, in Heidegger's version of the relationship, science may be said to be a peculiar kind of "applied" technology. At the least, this is an inversion of Platonism and may, in a curious sense, even continue to be called existential materialism. Ihde argued that "such an inversion specifically understood as a deliberated gestalt shift may first seem counter-intuitive. In Heideggerian inversion: science, rather than being the origin of technology, or technology as the application of science, becomes the tool of technology."

The systematic application of science to technology stirred a promise to research and modernization that promised an essential technological answer to all material wants. Endless growth in calculating devices of innumerable kinds flourished. Today, the typewriter gives way to the word processor that is far more useful than handwriting and typewriting. 
The combination of technological advancements, the opening and dominance of world markets, the campaign of worldwide implementation of the neo-liberal development paradigm of deregulation and liberalization, and intensifying business competition that has resulted in a global economic restructuring and integration are called globalization. Take, for instance, the computer business. Its trend has something to do with human creativity and innovativeness. The thrust is "to create something new," not copy others' products. Furthermore, companies market their manufacturing plants in Southeast Asia, China, and the United States.

For example, Samsung Electronics, a South Korean firm, has a development network in the US, Japan, Britain, Russia, India, and China. Samsung acquires its knowledge on production from Japan while research and development are patterned from the US. In the previous years, it was the leading maker of 256 megabytes $(\mathrm{Mb})$ DRAM (Dynamic RandomAccess Memory) chips. Finally, strategic alliance causes IT vendors and even electronic manufacturers to tie up with different projects.

As a result, to maintain their position in the global marketplace, some sectors invest in computers due to economic and social benefits despite their high price. Through merging assets, Dell Computers and Sony, for instance, are coming up with easy-to-use products. Their production, through alliances, gains more profits and cuts down costs (Ibon Facts and Figure 1996, 3-4).

Computers are becoming more and more a part of who we are as human beings. Along this line, issues regarding cyber technology with biotechnology developments and genome research arise. Ethical implications in the field of nanotechnology, as well as biochip implant technology, make it more difficult for us to separate certain aspects of our humanity from our technology. Computing devices are not seen as a mere extension but a part of our clothing and even of our bodies.

C. Most authors claim that normative confusion and ceaseless self-expansion define modernity and are merely reflected in technology as we know it. They resolve that humanity must move beyond supposedly neutral sociological, environmental, technological, spiritual, and philosophical explanations of how technologies arise and begin raising questions about the proper relationship between humanity and the shaping of technological order.

In The global imperative, Clark $(1997,35-44)$ proposed a sketch of globalization. According to his study, the globalization process is inseparable from the industrial system that organizes production power. He purported that globalization was made possible by society's ability to fashion the bulk flow technologies anywhere on the planet. Clark's ecomaterialistic views have profound ecological implications for Heidegger's philosophy. According to Heidegger, nature had been a target of domination, awaiting mastery. Clark incriminates "entropy" while Heidegger considers the manipulability of both human beings and nature the supreme danger of the essence of technology.

Roszak $(1969,7)$, in The making of counter culture, raised issues on technocracy. He means that "society in which those who govern justify themselves by appeal to technical experts who, in turn, justify themselves by appeal to scientific forms of knowledge." Beyond the authority of science, there is no other appeal. For Roszak, the roots of technocracy reached deep into our cultural past and are ultimately entangled in the scientific worldview of the West. His counter-culture questions the validity of the conventional scientific world and provides a critique of this dominant culture.

Corollary with Heidegger's thinking, Roszak $(1969,236)$ argues that our very existence is diminished when our concept of society is limited to objective consciousness. 
We become manipulated by science and technology. Roszak underscores that there must be a stance of life that seeks not simply to muster power against the misdeeds of society but to transform our concept of reality.

Ellul's The technological society argued that the technical phenomenon had become the defining political ideology of all modern societies. "Technique" or the technological mindset transforms means to ends to make value out of instrumental ones. Further, a technique has led to a confusion of means and ends in which society tends to transform the former into the latter. Finally, he called for an improbable spiritual transformation in response to the domination of technology.

For Morison (1966, 197), in Men, machines, and modern times, the system may have acquired a mass, scale, intricacy, and internal rate of change that made it increasingly difficult for human beings to live comfortably with it. While we significantly increased the production from each conversion, we also introduced numerous beneficial design modifications and succeeded in producing more. He argued that humanity has failed to advance the general understanding of the process. The problem is not scientific, but simply humanity.

In One Dimensional Man, Marcuse (1964, 50) deliberated upon "the logic of domination." Both inner and outer nature has been suppressed in the struggle for survival, at first against nature and later against other human beings in class society. He found the secret of psychic exploitation in repressive sublimation that led him to determine that technology affects society in its own right. Technology is independent of the social form under that it is organized. Liberation begins when we untie the domination.

The transcendent truth he invoked as a standard by which to evaluate society is not a realm apart from historical reality or a region of eternally valid ideas. It transcends the given historical reality. Ultimately, Marcuse sees, in art and religion, the rejection of social domination. Technical thinking, however, has taken over in every domain of life, human relationships, governments, and other fields.

\section{CONCLUSION}

How are we to assess the significance of Heidegger's questions? From the study on Heidegger and technology, the author has come to concur with Heidegger's vision, particularly concerning the outlook on globalization, namely, that "the goal of self-authentic self-determination by the individual is to be stripped of technological rationality, in its exploitative feature, that is the sole standard and guide in planning and developing the available resources for all" (Marcuse 1964, 251). The author agrees with Heidegger of rationality and the dominant tendencies of modern culture toward an ever more rational world. In its ever-greater progress, the rational mind increasingly reduced that which was not reasonable; reason was synonymous with the sensible (Featherstone 1995, 271-272).

The joint operation of technology and specialization, furthermore, restyle our environment and habits of attention in such a way that we run the risk of being turned into roles or animate abstractions; not turned into Platonic forms, through the actual passionate reaching toward an ideal, but rather into the type characters of comedy, in which each actor plays an assigned role predictably as though his life was something mechanical encrusted on the living (Brumbaugh 2018, 219). Probably, no age has talked more about "authenticity" but had less of it than our own. What we find in Greek poetry, medicine, and daily life, an awareness of the world in its full vividness and qualitative complexity, and engagement in politics, art, and ideas, dims because it has so little encouragement in our society. 
Globalization is a choice. It is a commitment, determination, and perseverance, which is more an effort of the heart than the mind alone. To achieve, we must commit. Only the heart can engage. To live an abundant life is to pursue our desires, our inner selves. We go after what fulfills us before making more money.

Nevertheless, though our understanding of things and ourselves as resources to be ordered, enhanced, and used efficiently has been forming since Plato, we are not trapped with that understanding. For Heidegger, once we realize that technology is our latest understanding of being, in our practices, not just as a matter of reflection -- we have stepped out of the technological sense of being (Guignon 1993, 306). We then see that what is most important in our lives is not subject to efficiency. Indeed, the drive to control everything is precisely what we do not control. This transformation in our sense of reality, this overcoming of thinking in values and calculation, is precisely what Heideggerian thinking seeks to bring about. Efficiency for its own sake is not the only end for humanity, dictated by reality itself, but just our current understanding.

In a world complacent with numerous advances in science and technology, it is no surprise that our goals and desires are tempered by the material society in which we find ourselves. Yet in The Question Concerning Technology, Heidegger $(1977,317)$ upholds: For questioning is the piety of thought. He urges us to strive to inspire to embrace independent thinking, look outside the system, and question what they are surrounded by. We are responsible for instilling value systems that will provide succeeding generations with a hunger for furthering the accepted boundaries and challenging preconceptions.

\section{ACKNOWLEDGMENTS}

Remembering Ernesto $(+)$ and Chalita $(+)$, the author's parents. Thanks also to her siblings for their continuous support and love for all her endeavors. She extends her gratitude to her relatives, friends, students and colleagues for their contributions to discourses in philosophy and their support to her person.

\section{BIBLIOGRAPHY:}

[1] Bradley, Stephen, et al., Globalization, technology, and competition: The fusion of computers and telecommunications in the 1990s, Boston, Harvard Business School Press, 1993.

[2Brumbaugh, Robert, Plato for the modern age, London, Muriwai Books, 2018, p.219.

[3]Cam, Philips, et al, Philosophy, culture and education: Asian Societies in transition. Seoul, ORUEM Publishing House, 1999. p.19, 192,197.

[4]Caputo, John, Demythologizing Heidegger: Aletheia and the myth of Being. Bloomington, Indiana University Press, 1993, 182.

[5]Clark, Robert, The global imperative. Colorado, Westview Press, 1997, p.35-44.

[6]Ellul, Jacques, The technological society, New York, Vintage Books, 1964.

[7] Featherstone, Mike, Global modernities. London, Sage Publications, 1995, p. 271-272.

[8] Feenberg, Andrew, Questioning Technology, London, Routledge, 1999, p. 195.

[9] Germain, Randall, Globalization and its critics: Perspectives from political economy. UK, Palgrave Macmillan, 2013.

[10] Guignon, Charles, The Cambridge Companion to Heidegger, Cambridge, Cambridge University Press, 1993, p.306.

[11] Heidegger, Martin, Discourse on thinking (Gelassenheit), Translated by John Anderson and Hans Freund, New York, Harper and Row, Publishers, 1969.

[12] Heidegger, Martin, Early Greek Thinking, Translated by David Farrell Krell and Frank Capuzzi, New York, Harper and Row, 1975.

[13] Heidegger, Martin, Letter on humanism, David Farrell Krell, New York, Harper and Row, 1977.

[14] Heidegger, Martin, Contributions to Philosophy (From Enowning), Bloomington, Indiana University Press. 2000. 
[15] Heidegger, Martin, On Time and Being, Chicago, University of Chicago Press, 2002.

[16] Heidegger, Martin, Basic writings: Martin Heidegger. Translated by David Farrell Krell, New York, Routledge, 2010.

[17] Heidegger, Martin, Poetry, Language and Thought. New York, Harper Publishers, 2013.

[18] Heidegger, Martin, Heidegger and the question concerning technology and other essays, Translated by William Lovitt, New York, Harper Torch books Publishers, 2017.

[19] Ibon Facts and Figures. "Technobabble on information technology." Ibon Foundation, Vol. 19. No. 21, (November 1996), p.3-4.

[20] Ihde, Don, Instrumental realism. The interface between philosophy of Science and Philosophy of Technology, Bloomington, Indiana University Press, 1991, p.55.

[21] Kockelmans, Joseph, Heidegger and science, Washington, University Press of America, 1985, p.250.

[22]Langan, Thomas, The meaning of Heidegger: A critical study of an existentialist phenomenology, New York, Columbia, p.1959. 159,196,199,174.

[23] Lovitt, Charles William and Harriet Brundage Lovitt. Modern technology in the Heideggerian perspective. New York, The Edwin Mellen Press, 1995, p.275, 430-432.

[24] Marcuse, Herbert. One-dimensional Man. London, Routledge and Keegan Paul, 1964, p.50-251.

[25] Morison, Elting, Men, machines, and modern times. Massachusetts, MIT Press, 1966, p.197.

[26] Polt, Richard. Heidegger: An introduction. New York, Cornell University Press, 2013.

[27] Roszak, Theodore, The making of a counter-culture, New York, Double Day and Co. Inc., 1969, p.236.

[28] Zimmerman, Michael, Heidegger's confrontation with modernity: Technology, politics, art, Bloomington, Indiana University Press, 1990, p. 231,233,247. 